\title{
ESTABILIDADE DA MOEDA NO PLANO REAL: POLÍTICA COMPENSATÓRIA?
}

\author{
Kelly Cardoso Faro ${ }^{1}$
}

\section{RESUMO}

O presente trabalho enfoca o estudo da política inflacionária brasileira na década de 1990 à luz do comportamento do Plano Real, não apenas em termos da estabilidade monetária, mas também em termos do desempenho empresarial, haja vista que a indústria brasileira nos anos 1990 sofre os reflexos do ambiente macroeconômico e das reformas estruturais implementadas no Brasil. A apresentação do programa de estabilização anterior - Plano Collor - se faz necessário para fins de equiparação e melhor elucidação dos resultados do Plano Real e da ação estatal no período. A estabilização dos preços fora alcançada, todavia se exacerbou as fragilidades competitivas da indústria nacional e não houve rearranjo fiscal tributário com elevação da progressividade, o que leva à crítica de que a estabilidade da moeda é necessária, porém seu papel de primazia enquanto objetivo de política econômica é controverso.

Palavras-chave: Estado brasileiro; Plano Real; Desempenho Empresarial

\begin{abstract}
This paper focuses on the study of Brazilian inflationary policy in the 1990s in the light of the behavior of the Real Plan, not only in terms of monetary stability, but also in terms of business performance, given that Brazilian industry in the 1990s undergoes the reflexes The macroeconomic environment and the structural reforms implemented in Brazil. The presentation of the previous stabilization program - Collor Plan - is necessary for the purpose of equating and better elucidating the results of the Real Plan and state action in the period. The stabilization of prices had been achieved, however, it exacerbated the competitive weaknesses of the domestic industry and there was no fiscal rearrangement with increasing progressiveness, which leads to criticism that the stability of the currency is necessary, but its role of primacy as a policy objective is controversial.
\end{abstract}

Keywords: Brazilian State; Real Plan; Business Performance

\footnotetext{
1 Docente do Curso de Ciências Econômicas da Universidade Federal de Mato Grosso - Campus Rondonópolis (UFMT/CUR). Discente do Programa de Pós-Graduação em Economia da Universidade Federal de Uberlândia (Doutorado - PPGE/UFU). E-mail: kcfaro@yahoo.com.br
}

Revista de Estudos Sociais | Ano 2017, N. 39, V. 20, Pag. 146 


\section{1 - INTRODUÇÃO}

A situação macroeconômica brasileira nos anos 1990 foi determinada, em grande medida, pelos problemas advindos da década anterior, sendo os principais a estagnação da atividade econômica e a inflação crescente, os quais acarretaram grande instabilidade no início da década de 1990. A partir de tal cenário, tem-se que o crescimento econômico brasileiro no período não se diferenciou muito daquele da "década perdida" ${ }^{2}$, mas sua dinâmica se alterou na medida em que, na última década do século XX, houve uma forte inserção internacional do país, ocasionada pelo intenso processo de abertura financeira, seguido de privatizações, elevação do consumo, da dívida pública, do Investimento Direto Externo (IDE) e da busca por mudanças estruturais, expressas na elevação dos gastos com infraestrutura.

O fato da década de 1990 ter apresentado um crescimento do PIB (Produto Interno Bruto) pouco superior ao da década anterior não permite que se ignore a importância de suas características particulares, principalmente em virtude dos planos de estabilização (os Planos Collor e Real). A nova dinâmica macroeconômica nacional nesta referida década é, portanto, o objeto de análise deste estudo, sendo que a apreciação dos pormenores do Plano Real em relação à estabilidade dos preços e ao desempenho das empresas serão priorizados.

Faz-se necessário também apresentar e avaliar o Plano Collor à medida que esse se torna ferramenta fundamental para fins de equiparação com o Real, haja vista que se estiver claro os objetivos daquele programa, assim como as estratégias de reforma econômica colocada em ações e, depois for feita uma avaliação dos seus resultados, é possível distinguir de forma mais nítida as diferenças entre os planos e, portanto entre os seus efeitos na estabilidade de preços que, diga-se de passagem, foi mais exitosa no Plano Real.

O objetivo central é mostrar que as políticas adotadas no Brasil neste período não são políticas universais, pelo contrário, são políticas desconexas, entrecortadas, que não podem nem ser chamadas de compensatórias, dado que políticas compensatórias

\footnotetext{
${ }^{2}$ Expressão cunhada pela literatura econômica para se referir à década de 1980 da economia brasileira.
}

Revista de Estudos Sociais | Ano 2017, N. 39, V. 20, Pag. 147 
procuram atender deficiências de uma política universal e as políticas no Brasil na década de 1990 tinham a primazia exclusiva do controle dos preços.

Deste modo, o presente trabalho encontra-se dividido em três seções, incluindo esta breve introdução. A segunda seção procura apresentar a concepção do Plano Collor, bem como as medidas efetivamente tomadas e seus respectivos resultados, enquanto que a terceira seção compreende uma análise do Plano Real, incluindo desde a origem da reforma monetária até o efetivo controle inflacionário e, ainda averiguando os respaldos nas empresas. Por fim, à guisa de conclusão, serão apresentadas as considerações finais do estudo.

\section{2 - O PLANO COLLOR}

No dia 15 de março de 1990 Fernando Collor de Mello assume a Presidência do Brasil e, no dia seguinte à sua posse, com o intuito de buscar concretizar as promessas feitas no período eleitoral, ele anuncia o Plano Collor, um pacote de medidas com vistas ao combate à "hiperinflação" que se pronunciava. Além disso, o Plano tinha um caráter híbrido porque buscava conciliar políticas ortodoxas e heterodoxas no controle da inflação (OLIVEIRA, 1992).

A aceleração da inflação, associada à perda do valor da moeda nacional, era um sinal claro da hiperinflação latente, que acompanhada de uma dificuldade do Estado em adotar políticas econômicas capazes de contê-la de forma eficaz e permanente, fizeram com que a visão dos formuladores do Plano $^{3}$ fosse a de que o país passava por uma profunda crise de Estado, sendo essa de amplitude fiscal, financeira e política, o que impossibilitava o controle do nível de preços. Dessa forma, as principais medidas seriam as de promover uma reforma monetária que viabilizasse uma melhoria estrutural e administrativa, uma reformulação no papel do Estado e a mudança no padrão monetário.

Segundo Oliveira (1992), a reforma administrativa fazia parte da campanha contra os marajás; o padrão monetário se reformulou, com a extinção do Cruzado Novo e a volta para o Cruzeiro, sem eliminação de dígitos; a política fiscal incidiu mais sobre a questão patrimonial, já que houve a privatização de empresas públicas de setores estratégicos

\footnotetext{
${ }^{3}$ O Plano Collor foi teorizado por Antônio Kandir, Álvaro Zini e Fábio Giambiagi; todavia, o Plano que fora colocado em prática foi desenvolvido por Zélia Cardoso de Mello, Antônio Kandir, Ibrahim Eris, Venilton Tadini, Luís Otávio da Motta, Eduardo Teixeira e João Maia (CARVALHO, 2006).
}

Revista de Estudos Sociais | Ano 2017, N. 39, V. 20, Pag. 148 
(como o siderúrgico); e a liberalização da taxa de câmbio seria uma política de curto prazo.

Já a reforma monetária seria a mais radical, pois incluiria o confisco de ativos financeiros que excedessem 50 mil cruzeiros para poupança e 25 mil para depósitos a vista, recursos esse que seriam devolvidos em 12 parcelas após 18 meses. Essa medida ortodoxa gerou um forte arrefecimento da liquidez e certo descontentamento, porque os efeitos dessa ação variavam de acordo com a classe social, as famílias teriam sua liquidez reposta no período seguinte de recebimento dos salários, mas as empresas apresentaram dificuldades de efetuar o pagamento dos salários, o que acarretou diversas ações judiciais pedindo o adiantamento da restituição.

Oliveira (1992) destaca a importância do confisco enquanto mecanismo de redução do endividamento público, já que reduz os juros e eleva o período de vencimento; porém, considera também de pouca eficiência esse método para o controle inflacionário.

Com relação à reforma do Estado, o objetivo era torná-lo menos interventor e mais regulador, segundo as palavras de Pinheiro, Giambiagi e Gostkorzewicz (p.13-14, 1999):

O papel do Estado na economia mudou de forma drástica, passando de um Estadoempresário, que procurava impulsionar o desenvolvimento econômico definindo diretamente onde os fatores de produção deveriam ser alocados, para um Estado regulador e fiscal da economia. A prioridade não era mais a simples acumulação de capital, mas a busca da eficiência, com o mercado substituindo o Estado na definição da alocação de recursos. Dessa maneira, o novo modelo de desenvolvimento caracteriza-se por uma economia mais aberta, com maior integração com o resto do mundo, não apenas no que tange aos fluxos comerciais, como também ao investimento direto estrangeiro.

Todavia, é importante ressaltar que esse argumento expresso acima não é consensual na literatura econômica e que por isso, não se pode dizer que a atuação do Estado ocorreu ferrenhamente nesses moldes, inclusive há longa discussão na literatura afirmando ser a ausência de um projeto nacional de desenvolvimento a razão de não termos um desenvolvimento e crescimento econômico perene.

Em termos comparativos, podemos dizer que o Plano Collor foi mais abrangente e radical do que os Planos Verão e Cruzado (ambos da década de 80) à medida que deixou claras as intenções de elevar a liberalização comercial e o superávit público. Contudo, as observações de Carneiro (2002) sugerem que nos dois primeiros meses seguidos da implantação do Plano Collor, a inflação já havia voltado, assim como o ambiente econômico recessivo, o que aproxima o Plano Collor dos planos que tinham a finalidade

Revista de Estudos Sociais | Ano 2017, N. 39, V. 20, Pag. 149 
de controlar os níveis de preço da década anterior, haja vista que esses planos também não lograram êxito duradouro no controle da inflação.

Com o então "fracasso" do Plano Collor, associado ao retorno da inflação, a visão política que se tinha até então era a de que a tentativa de se conciliar políticas ortodoxas e heterodoxas não funcionou. Então, entrou em vigor uma tentativa de volta à ortodoxia no combate à inflação, com o Plano Collor II.

\section{1 - Plano Collor II}

Esse novo Plano anuncia uma política industrial que determinava metas e importância dos setores produtores de bens industriais, tendo surgido às câmaras setoriais; todavia, a medida mais marcante foi à reforma ministerial que substituiu a ministra Zélia Cardoso de Mello pelo conservador Marcílio Marques Moreira, de manifesta tendência favorável à reaproximação do Brasil ao sistema financeiro global, preocupado em negociar a dívida externa e tentar um combate gradual à inflação (CARNEIRO, 2002).

Ademais, a abertura financeira internacional foi bem-sucedida, em certa medida, porque o cenário internacional estava num momento de excesso de liquidez, o que levou a aumento das reservas por conta da entrada de capital externo no país, conferindo ao Brasil uma situação aparentemente confortável do ponto de vista externo. Entretanto, internamente a situação não era favorável, pois a situação política era instável devido ao processo de impeachment do então presidente Fernando Collor de Mello, em uma conjuntura marcada por taxas de juros elevadas, sob a gestão do ministro Marcílio Moreira.

O período Collor, apesar de breve, foi bastante intenso em termos econômicos e políticos. No que concerne às questões econômicas, o que se pode notar é que as ações dos Planos Collor I e II foram pouco eficazes em seu objetivo básico e fundamental de controlar a inflação e manter a estabilidade monetária, mas também se mostraram cruciais na determinação de alguns avanços como o fim do processo de substituição de importação (PSI) e o início de mudanças estruturais no país. Contudo, as ações ligadas à abertura econômica foram muito rápidas e intensas, assim como suas repercussões, o que, conciliado com um ambiente recessivo e de pouca proteção, levou a falência de inúmeras empresas.

Revista de Estudos Sociais | Ano 2017, N. 39, V. 20, Pag. 150 
Após o impeachment de Collor, a Presidência é assumida pelo então vicepresidente, Itamar Franco, cujo governo se apresentou como de transição, com a incumbência de determinar a orientação da política econômica. A direção seguida pela política demorou um pouco a ser definida e, juntamente com a alternância de ministros da Fazenda, são as características fundamentais desse período (CARNEIRO, 2002).

Por fim, temos que o Governo Itamar se destaca por ter idealizado e implementado o último Plano de Estabilização, o Plano Real, na vigência do então Ministro da Fazenda Fernando Henrique Cardoso.

\section{3 - O PLANO REAL}

Sabe-se que o Brasil era assolado pelo problema da hiperinflação latente desde a década de 1980, tanto que vários programas foram acionados na tentativa de reverter esse processo, como os Planos Verão, Bresser e o Cruzado. No entanto, é também de conhecimento que estes não foram bem-sucedidos, bem como o Plano Collor, explanado na seção anterior, esse já no início da década de 1990.

Alguns economistas e estudiosos do tema acreditam que a causa desse insucesso tenha sido a ausência de uma reforma monetária realmente austera e problemas relativos ao controle e administração do congelamento de preços. Nesse ponto é que entra em foco um programa cujas origens teóricas são genuinamente brasileiras, que conseguiu sim dar conta do problema da hiperinflação que se anunciava da forma mais inesperada possível: a antecipando de forma controlada a fim de ela se auto ajustasse posteriormente.

Esse é o Plano Real que será apresentado e avaliado com maior atenção nessa seção e, que cujo objetivo de estabilização estava tão acentuado que acabou deixando um pouco de lado as questões referentes ao desempenho singular dos setores e das empresas; ação que essa que se reverteu após os bons resultados em termos de estabilização e que também é foco de estudo dessa seção.

\section{1 - Contexto e Descrição Analítica do Plano}

Revista de Estudos Sociais | Ano 2017, N. 39, V. 20, Pag. 151 
Filgueiras (2006) coloca o chamado Consenso de Washington ${ }^{4}$ e o Plano Cruzado como as duas principais referências para a construção do Plano Real, a primeira contribuindo com os insumos teóricos e ideológicos e a segunda com as lições sobre o que não se deveria repetir como política econômica.

Antes de o Plano Real ter sido colocado em prática, adotou-se o PAI (Plano de Ação Imediata), que anunciava a busca do equilíbrio das contas públicas como requisito necessário para se combater a inflação, equilíbrio esse identificado como algo a ser alcançado via cortes orçamentários e reordenação dos gastos públicos.

O PAI, por sua vez, não apresentou grandes resultados em termos de queda na inflação, porque os mecanismos de indexação ${ }^{5}$ haviam voltado fortemente no período pós Plano Collor. Com isso, a equipe econômica, composta inclusive pelos economistas Pérsio Arida, André Lara Resende e Edmar Bacha idealizou um plano de estabilização econômica pautado em uma reforma monetária austera, pois se acreditava que a inflação brasileira era inercial ${ }^{6}$ (CARNEIRO, 2002).

A fim de incidir diretamente sobre o componente inercial da inflação, a Reforma Monetária do Plano Real incluía três etapas, sendo a primeira a implantação do FSE (Fundo Social de Emergência), a seguinte a introdução da URV (Unidade Reserva de Valor) e, por fim, a efetiva introdução da nova moeda, o Real.

O FSE era uma estratégia de equilíbrio orçamentário, com a reorganização das finanças públicas, se apresentando como uma medida de curto prazo que buscava ajudar na reordenação das contas públicas, apesar de que se tinha claro que essa questão só seria resolvida com as reformas estruturais. Faz-se mister ressaltar que a etapa seguinte, da introdução da URV, se iniciou sem que essa etapa fosse cumprida.

A URV era uma moeda fictícia, com função de unidade de conta, com referência no dólar americano, o que significa que o valor da URV era a taxa de câmbio de então. Ressalte-se que essa não foi uma moeda propriamente dita, por não ter circulado como

\footnotetext{
${ }^{4}$ Cartilha elaborada por John Williamson em 1989 que vigorou como uma recomendação internacional que visava a propalar a conduta econômica neoliberal com a intenção de combater as crises e misérias dos países subdesenvolvidos, sobretudo os da América Latina (FILGUEIRAS, 2006).

${ }^{5}$ A indexação, em economia, é um sistema de reajuste automático de preços, inclusive salários, em situações inflacionárias. Assim, na medida em que a inflação aumenta os preços precisam ser ajustados para que não fiquem defasados (CARNEIRO, 2002).

${ }^{6}$ Inflação inercial é a aquela em que a inflação presente é uma função da inflação passada. Isso se deve à inércia inflacionária, que é a resistência que os preços de uma economia oferecem às políticas de estabilização que atacam as causa primárias da inflação. Assim, a "indexação" é o reajuste do valor das parcelas de contratos pela inflação do período passado (CARNEIRO, 2002).
}

Revista de Estudos Sociais | Ano 2017, N. 39, V. 20, Pag. 152 
papel moeda. O conceito para a introdução da URV era de que ela funcionasse como único indexador da economia, tendo seu valor em cruzeiros anunciado todos os dias pelo Banco Central (CARNEIRO, 2002).

A ideia era fixar todos os preços em URVs, uma nova moeda que se autocorrige. Tal situação jamais pode ser possível se fazer no Brasil, mesmo que de forma similar, porque os trabalhadores e a própria sociedade resistem à ideia de congelar os salários pela média, mas como seus salários foram fixados em URVs e os trabalhadores não sabiam bem o que era, ocorre uma aceitação geral (NETTO, 1998).

Foi estipulado um prazo para que todos os preços e contratos fossem convertidos em URV, o que acarretou subida dos preços e elevação exacerbada da inflação, resultando em hiperinflação e conjunção de todos os preços num único indexador. Tal situação foi induzida a fim de provocar a ocorrência do que Lara e Arida já tinham enunciado em 1986, “a hiperinflação carrega em si mesmo a semente da sua autodestruição" (NETTO; p. $10 ; 1998)$.

À medida que a inflação se acelerava os preços eram reajustados com uma temporalidade menor, o que eleva cada vez mais a inflação e faz com que os preços convertam cada vez mais para o mesmo valor. $\mathrm{O}$ reajuste passa a se dar por um único indexador, produzindo-se assim uma hiperinflação para acabar com o problema da assimetria dos preços.

A etapa seguinte, após o controle dos preços, foi à introdução da nova moeda, o Real, que se deu em julho de 1994, e seguia a referência de um URV, a partir da seguinte fórmula: 1 real = $1 U R V=1$ dólar $=2750$ cruzeiros. Tal medida, segundo Carneiro (2002), resgatou a função de reserva de valor da moeda nacional, agora o Real, e a paridade se deu pelo acúmulo de reservas derivado da situação internacional favorável, e pela política cambial de bandas assimétricas, em que o Banco Central permitia a apreciação da moeda - mas não sua depreciação, o que permitiu ao governo o controle da inflação e a garantia da paridade, fator esse que ocorria por conta da abertura comercial e financeira.

Filgueiras (2006) alega em linhas gerais que os elementos fundamentais do Plano foram os que mantiveram a inflação em níveis muito baixos, porém os mesmos não foram capazes de retirar o país da armadilha que o contrapunha em que, de um lado, se tinha inflação reduzida com estagnação econômica ou crescimento medíocre e elevados níveis de desemprego e, de outro, crescimento mais elevado com risco de crise cambial.

Revista de Estudos Sociais | Ano 2017, N. 39, V. 20, Pag. 153 
Esta foi uma descrição sucinta do Plano Real, todavia o mesmo foi bastante estudado e seus resultados/consequências são ainda debatidos na literatura. O Quadro 01 apresenta alguns importantes ensaios, de diferentes interfaces metodológicas, que apresentam o Plano Real pormenorizadamente.

\section{Quadro 01}

Revisão de Literatura: Plano Real

\begin{tabular}{|c|c|c|}
\hline Autor (es) & Ano de Publicação & Objetivo \\
\hline Bresser Pereira & 1995 & $\begin{array}{l}\text { Explica de forma pormenorizada as três fases do Plano Real, } \\
\text { a saber: i) a reforma monetária; ii) adoção da URV (Unidade } \\
\text { de Reserva de Valor) e iii) adoção do Real. }\end{array}$ \\
\hline Batista Jr & 1996 & $\begin{array}{l}\text { Analisa os primeiros dois anos do Plano Real, } \\
\text { os seus efeitos sobre as relações econômicas externas do } \\
\text { Brasil à } \\
\text { da experiência de programas de estabilização semelhantes } \\
\text { adotados no México (1988) e na Argentina (1991). }\end{array}$ \\
\hline Faria & 2004 & $\begin{array}{l}\text { Faz uma retrospectiva da economia brasileira } 10 \text { anos após o } \\
\text { Plano Real. O autor alega que apenas a inflação baixa } \\
\text { permaneceu e que a inserção internacional do Brasil e a } \\
\text { política macroeconômica que adotada são as responsáveis } \\
\text { pela estagnação econômica e crise social. }\end{array}$ \\
\hline Fernandes e Toro & 2005 & $\begin{array}{l}\text { Pesquisa empírica que estima o mecanismo de transmissão } \\
\text { monetária da economia brasileira pós-Plano Real } \\
\text { correlacionada ao estoque real de moeda, renda real agregada, } \\
\text { inflação e taxas de juros de curto e longo prazo. }\end{array}$ \\
\hline $\begin{array}{c}\text { Lara e Carvalho } \\
\text { Mesquita }\end{array}$ & 2008 & $\begin{array}{l}\text { Pesquisa empírica que verificou qual a influência da estrutura } \\
\text { de capital de empresas } \\
\text { brasileiras sobre a rentabilidade. Os autores utilizaram dados } \\
\text { do pós implantação do Plano Real para internalizar as } \\
\text { influências da redução das taxas de inflação, aumento das } \\
\text { taxas de juros e instabilidade da política cambial. }\end{array}$ \\
\hline Lopes e Conceição & 2016 & 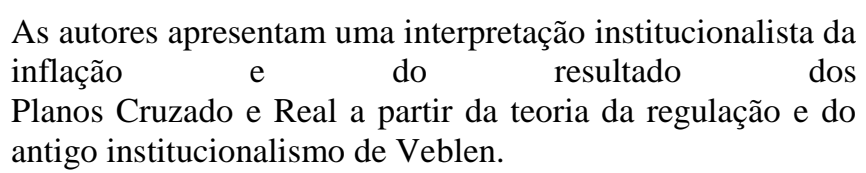 \\
\hline
\end{tabular}

Revista de Estudos Sociais | Ano 2017, N. 39, V. 20, Pag. 154 


\begin{tabular}{l|l|l} 
Moura e Marinho & 2017 & $\begin{array}{l}\text { Avaliação das mudanças políticas e econômicas no pós-Plano } \\
\text { Real em detrimento da inserção das empresas brasileiras no } \\
\text { mercado internacional. }\end{array}$ \\
\hline
\end{tabular}

\section{2 - O Desempenho e Estratégia das Empresas na Vigência do Plano Real}

Nos anos 1990, por sua vez, a política industrial e de comércio exterior se direcionavam rumo à adaptação ao novo paradigma internacional. Em função do quadro de instabilidade reinante na economia brasileira praticamente durante todos os anos 1980, grande parte dos setores da economia brasileira encontrava-se em atraso tecnológico, comparativamente aos padrões internacionais. Por isso, da política de liberalização da economia, que apesar de ter acontecido mais tarde no Brasil do que em outros países em desenvolvimento, se iniciou com a crença de que o livre-comércio desencadearia o desenvolvimento econômico, com a consequente melhoria da qualidade de vida da população, proporcionado pelo crescimento econômico advindo da melhor eficiência alocativa dos fatores de produção.

Na primeira metade da década de 1990, a situação era de inflação elevada, baixos níveis de produtividade industrial e retração da atividade econômica, produto direto das medidas fiscais e monetárias recessivas adotadas, a fim de impedir a continuidade do processo inflacionário. As tentativas de combate à inflação e a reestruturação que se vislumbrava fez com que o início da década fosse marcado pelo forte impacto da recessão interna, no aumento do desemprego, queda nos salários reais e na massa salarial.

A inflação conseguiu ser arrefecida em 1994, com o Plano Real, como mostra o Gráfico 01, todavia o ambiente econômico que se via no período pós-real era de não solução para a equação do crescimento. Como a capacidade instalada não cresce tanto quanto deveria, qualquer movimento de crescimento de consumo é abordado através de medida de restrição de crédito, elevação dos juros e aumento dos compulsórios, de forma que o crescimento se torna um subproduto e, não o objetivo principal da política econômica. Além do mais, o fraco desempenho das exportações se seguiu até o final da década de 90, mesmo após o Plano Real, houve na verdade, uma mudança estrutural na economia brasileira, com a diminuição da produção local pelas importações.

\section{Gráfico 01}

Revista de Estudos Sociais | Ano 2017, N. 39, V. 20, Pag. 155 


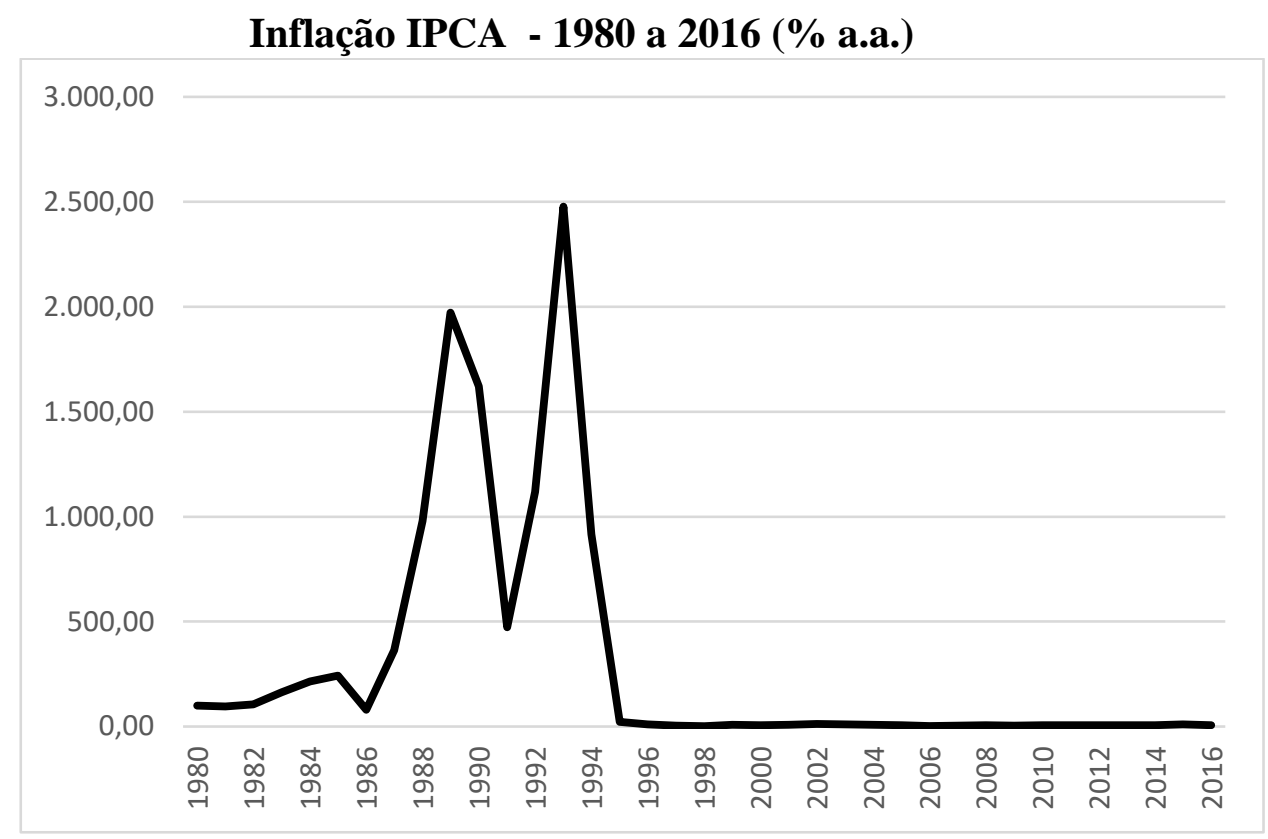

Fonte: IBGE (2016)

Bogdanski, Tombini \& Werlang (2000) apontam que o Brasil, mesmo após passar pelo gradualista processo de estabilização do Plano Real, era suscetível a choques externos por não ter conseguido sanar os problemas econômicos estruturais do país.

O crescimento da economia implica um aumento da propensão a importar. Adicionalmente, quando o mercado interno está aquecido, os produtores tendem a se voltar para o seu atendimento, geralmente em condições mais rentáveis devido à situação cambial. A elevação das importações, por sua vez, desestimula a produção interna de determinados itens, devido a perde de competitividade frente aos produtos internacionais mais baratos.

Cabe destacar que a expansão do mercado interno é tida por Furtado (1998) como o meio necessário à formação de um sistema econômico autônomo na formação de poupança e geração de demanda efetiva. Ademais, é a forma pela qual as sociedades preservam sua identidade cultural e unidade política.

Nas palavras de Lacerda, “(...) a crise dos anos 1980-1990 é considerada uma crise de esgotamento de um padrão de desenvolvimento excludente e incapaz de dar conta da incorporação dinâmica à economia internacional (p. 43, 1998)”.

O trabalho de Castro (1997) é bastante elucidativo nessa seção porque ele se propõe a averiguar como seu deu o posicionamento das empresas na vigência do Plano Real além, de também verificar como o governo se posicionou frente às necessidades do setor produtivo nacional aquela época.

Revista de Estudos Sociais | Ano 2017, N. 39, V. 20, Pag. 156 
Segundo o autor na fase inicial do então atual programa de estabilização as autoridades governamentais se negavam a ter em conta questões situadas em nível setorial e de empresas em particular. Para eles, as decisões das empresas, relativas ao uso singular dos recursos sob controle, não deveriam sofrer interferências procedentes dos poderes públicos.

Todavia, na vigência do Plano Real a situação se inverteu e o governo passava a se interessar vivamente pelo desempenho singular de setores e empresas. A iniciativa e responsabilidade pelas decisões permaneceram claro, nas mãos das empresas. Mas o governo, além de 'apostar' no desempenho dos empresários em elevar incessantemente a produtividade, passava a deixar claro sua disposição em interferir e negociar apoios e estímulos. Assim, a base da aposta governamental seria o aumento da produtividade e a discussão do texto gira, por isso, nas formas de estratégias empresariais que possibilitam esse aumento.

Retomando o histórico de produtividade nacional, vê-se que na década de 1970, temos algo próximo do ideal, por assim dizer, pois o pessoal ocupado cresce firmemente, a produtividade se eleva rapidamente e a produção avança mais do que as demais variáveis. Já nos anos 1980, a produtividade inicialmente cresce, mas este resultado se combina com um forte declínio do emprego. Segue-se, na metade da década, virtual estagnação da produtividade.

$\mathrm{Na}$ década de 1990, o indicador de produtividade dispara inicialmente acompanhado de redução de emprego, mas depois se têm algo inédito: o crescimento da produção se combina com redução do emprego, associada a um acelerado crescimento da produtividade.

Todavia, é importante ressaltar que a produtividade não deve se confundida com uma elevação da terceirização para fora do Brasil ou com um aumento de competitividade, pois isso seria um equívoco. A produtividade aqui se refere a do trabalho, se traduzindo, portanto, em redução dos custos unitários de produção. A partir dessa óptica, e retomando a queda acentuada de produtividade da segunda metade da década de 80 , vê-se que o progresso técnico, que avançava a grande velocidade no exterior, deixou de ser introduzido no país, configurando assim um fenômeno de retardamento tecnológico que, anunciava uma possibilidade de recuperação nos anos seguintes.

Revista de Estudos Sociais | Ano 2017, N. 39, V. 20, Pag. 157 
$\mathrm{O}$ aumento de produtividade visto posteriormente esteve ligado não só à recuperação que era esperada, mas as melhorias incrementais, obtidas principalmente em investimentos no processamento de materiais e no uso de novos equipamentos, além de estar muito ligado às mudanças de estratégias por parte das empresas, sendo que essas não são facilmente definidas. Por isso, o autor definiu três diferentes linhagens estratégicas. A primeira linhagem estratégica se caracteriza pela busca do rebaixamento de custos, os recursos acionados com esse objetivo são de enorme variedade.

Já a segunda linhagem estratégica está centrada na mudança, ampliação e/ou realocação de capacidade, enquanto que a terceira linhagem estratégica caracteriza-se por redefinições patrimoniais/empresariais. Incluem-se aqui desde a busca de sócios e o estabelecimento de parcerias, até a fusão ou transferência de controle.

Por fim, Antônio de Castro (1997) coloca uma questão interessante para o debate sobre os novos desafios para o crescimento da produtividade da indústria brasileira, ele concorda que o aumento da produtividade alcançado na economia brasileira em decorrência das estratégias empresariais anteriormente mencionadas foi, sem dúvida, elevado. No entanto, considera que, a partir de certo ponto, a continuidade desse aumento tende a perder ímpeto, porque várias dessas estratégias são "soluções cirúrgicas" (p.118) que visavam reduções de custos a curtíssimo prazo e foram alcançadas antes por ruptura ou descontinuidades do que por evolução contínua, centrada em processos rotineiros de introdução de inovações.

Dessa forma, nota-se que o autor remete a melhora da produtividade das empresas ao esforço singular das mesmas à medida que a política econômica vigente as instituiu dessa responsabilidade, ainda que indiretamente, quando se focalizou na busca pela estabilidade do nível de preços, ficando o governo a disposição para interferir e negociar apoios e estímulos mas, a cargo dos setores e empresas a responsabilidade pelos bons resultados.

Na opinião de Franco (1998) à implantação do Plano Real, que teve como a mais importante de todas as premissas a vitória sobre o controle inflacionário, que deveria ter sido consolidada sobre um novo modelo de desenvolvimento para o país.

Os eixos pilares de transformação desse modelo, segundo o autor, eram as privatizações e a produtividade. $\mathrm{O}$ crescimento da produtividade era a única forma de se conseguir, ao mesmo tempo, maiores salários e menores preços, pois se conseguiria mais competitividade sem inflação e a desvalorização cambial favoreceria o dinamismo

Revista de Estudos Sociais | Ano 2017, N. 39, V. 20, Pag. 158 
tecnológico a medida que elevaria a produtividade pelo favorecimento da competição e não pela falta dela.

Franco (1998) também avalia que houve também uma redistribuição, ainda que relativa, setorial e regional da atividade manufatureira com o propósito de permitir um melhor enfrentamento do desafio competitivo. Ocorre então, desemprego em alguns setores e regiões, enquanto que outros experimentam expansão inusitada.

A apresentação de indicadores selecionados feita por Lara e Carvalho Mesquita (2008), apresentadas abaixo no Quadro 02, para o período imediatamente posterior ao Plano Real (1995-2001) justifica os resultados apresentados pelas empresas nacionais. As taxas de juros tanto de longo quanto de curto prazo (expressa pelo financiamento de capital de giro) foram reduzidos considerando a média dos dois subperíodos que poderiam ter contribuído por resultado das empresas. Todavia, o PIB (Produto Interno Bruto) apresenta grande oscilação nos anos selecionados o que acentua o grau de incerteza enfrentado pelos empresários, que afeta diretamente o investimento produtivo. Ademais, as empresas tiveram que profundas reformas pós-1994 dado que as constantes elevações de preços mascaravam ineficiências operacionais e a política cambial adotada no Real acirrava a concorrência com empresas estrangeiras pela cotação real por dólar as privilegiar frente as empresas domésticas.

\section{Quadro 02}

Brasil - Indicadores selecionados (1995-2001)

\begin{tabular}{ccccc}
\hline Ano & $\begin{array}{c}\text { TJLP } \\
\text { (\% mês) }\end{array}$ & $\begin{array}{c}\text { Financiamento capital } \\
\text { de giro }(\% \text { mês) }\end{array}$ & $\begin{array}{c}\text { Taxa de câmbio } \\
\text { (RS/US\$, média anual) }\end{array}$ & $\begin{array}{c}\text { PIB real } \\
\text { (variação \% anual) }\end{array}$ \\
\hline 1995 & 1,7658 & 3,2000 & 1,0072 & 4,2 \\
\hline 1996 & 1,2476 & 2,7208 & 1,0800 & 2,7 \\
\hline 1997 & 0,8073 & 2,4892 & 1,1636 & 3,3 \\
\hline 1998 & 0,9230 & 2,5083 & 1,8506 & 0,1 \\
\hline 1999 & 1,0398 & 1,9458 & 1,8340 & 0,8 \\
\hline 2000 & 0,8543 & 2,1442 & 2,3524 & 4,4 \\
\hline 2001 & 0,7592 & 2,3192 & 2,9975 & 1,5 \\
\hline Média 95-98 & 1,1859 & 2,7296 & 1,2753 & 2,6 \\
\hline Média 99-01 & 0,8844 & 2,1364 & 2,3946 & 2,2 \\
\hline
\end{tabular}

Fonte: Lara e Carvalho Mesquita (p.16; 2008)

Para Coutinho (1998), a abertura econômica e o Plano Real teriam provocado inicialmente, um processo, por ele apontado como "desindustrialização" ou de regressão tecnológica/especialização regressiva da indústria brasileira. Todavia, pode-se

Revista de Estudos Sociais | Ano 2017, N. 39, V. 20, Pag. 159 
argumentar, a favor de Coutinho, que o setor de baixa tecnologia também ganha importância no período 1985-1998, e ainda é o de maior peso na indústria. Nitidamente o segmento que perde espaço na estrutura industrial é o de média baixa tecnologia.

Ademais, tal situação, segundo Coutinho (1998), é na verdade um processo difícil e doloroso de reestruturação, mas que fez com que, posteriormente, dentro de dois ou três anos após a reforma do Plano Real, a indústria emergisse ajustada e competitiva.

Deve ser destacada a ausência notória de políticas universais no Brasil o que implica que as modificações na conjuntura nacional não são características de transformações estruturantes o que revela ausência de um projeto nacional e revela que as políticas nacionais são pautadas pela desconexão de um bem comum, de norte estatal.

\section{3 - Principais Resultados do Programa}

Os resultados mais imediatos da reforma monetária foram à queda abrupta da inflação em 1994, a deterioração do saldo comercial, advindo da incapacidade do país em arcar com uma moeda tão valorizada, e a elevação do consumo pelo ganho de poder real de compra com a estabilização dos preços.

De acordo com Bacha (p. 11, 1997), a reforma monetária do Plano Real teve o mérito de "conseguir a estabilização sem recessão, sem congelamento e sem confisco de ativos financeiros"; como houve no Plano Collor, em contraposição, também a obteve sem crescimento econômico.

As demais ações, além do ajuste fiscal e da desindexação da economia, compreendidas pelo Plano Real, foram (i) a política monetária restritiva, com a elevação da taxa básica de juros e aumento dos depósitos compulsórios; (ii) a redução das tarifas de importação, por conta do excesso de demanda, e (iii) a manutenção do câmbio valorizado para manter elevada a oferta interna de produtos. Essas ações foram tomadas em 1995, já que com a crise do México, o Brasil foi "golpeado" (BACHA, 1997) pelo aumento e exacerbação dos desequilíbrios entre demanda e produção, e salários e preços.

Contudo, era notório que o crescimento econômico era incompatível com as elevadas taxas de juros, pois essas acarretam elevação da vulnerabilidade, evasão de reservas e déficits na balança de comércio, haja vista que as importações estavam crescendo mais do que as importações. Tais fatores, associados ao câmbio desfavorável, restringiam os ganhos de produtividade da economia (Carneiro, 2002).

Revista de Estudos Sociais | Ano 2017, N. 39, V. 20, Pag. 160 
Essa situação é o que o Delfim Netto (1998) chamou de "Armadilha do Crescimento", que em outras palavras é o mecanismo de elevação do déficit público à medida que se tem um crescimento econômico positivo acompanhado de um aumento da vulnerabilidade externa e consequente fuga de capitais, restando assim a alternativa de se conter o crescimento econômico nacional.

Um breve balanço sobre as conseqüências macroeconômicas da instituição do Plano Real e das ações adotadas para se manter os seus objetivos básicos - mesmo após a efetivação de suas medidas, requer que sejam apresentadas visões que mostram de forma sucinta e clara a dinâmica macroeconômica pós-Plano Real. A primeira visão é de Pinheiro, Giambiagi e Gostkorzewicz (pp. 34-35, 1999) em que os autores afirmam que:

\begin{abstract}
De um lado, a evolução de alguns dos indicadores macroeconômicos tradicionais não permite qualquer comemoração, já que os números falam por si: o crescimento econômico foi apenas moderado e a taxas declinantes; o desemprego subiu; o déficit público foi alto; o endividamento público aumentou a grande velocidade; e o setor externo caracterizouse pelo baixo crescimento das exportações e por elevados déficits em conta corrente. De outro, é inegável que a estabilização representou melhoria substancial com relação à situação experimentada pelo país em 1981-1993; além disso, foram feitas reformas importantes que poderão propiciar as condições para um ciclo expansionista na próxima década.
\end{abstract}

A outra visão, não conflitante com a anterior, mas que retrata os resultados enfatizando a questão da inflação e do crescimento econômico é representada por Bacha (p. 65, 1997), e advoga que:

A conclusão principal é que o Plano Real não apenas foi bem - sucedido em baixar as taxas de inflação, mas também em mantê-las baixas. Entretanto, o Plano Real ainda não foi bem-sucedido em produzir uma tendência econômica na qual o controle inflacionário é compatível com o crescimento econômico sustentado e um razoável equilíbrio externo.

É possível perceber que, no Plano Real, segundo Netto (1998), foi criado um mecanismo, denominado URV, que foi capaz de reproduzir todas as condições de hiperinflação, sem ter que passar pelos males que a verdadeira causa. Ocorre então no Brasil, com o Plano Real, uma série de 'coisas interessantes' (p. 41) dentre elas a queda rápida dos preços, alto crescimento da demanda e queda abrupta da demanda nos doze primeiros meses, além de uma situação de melhora relativa na distribuição de renda e na liberalização do crédito num período inicial.

Todavia, esse processo produziu desequilíbrios no processo produtivo, na medida em que no início dele houveram mecanismos de restrição de crédito e de elevação 
(necessária) das taxas de juros. Isso constrói uma armadilha, segundo o autor, que impede o crescimento da economia, pois cada vez que a economia começa a crescer tem-se intenso déficit público. Essa situação fez com que a economia entrasse num período de stop and go.

A esperança do governo era a seguinte: aumentar as exportações sem mexer no câmbio. Contudo, toda essa corrida para reduzir o "custo Brasil", para arrefecer os impostos nas exportações e para tentar chamar a atenção dos investidores internacionais e eliminar as restrições externas foram construídas pelo próprio processo de estabilização, pensado e implantado com estes objetivos.

A resposta então para a saída da armadilha seria pela expansão das exportações, e sem mexer no câmbio, segundo o governo, mas tal política não foi suficiente para a reversão do processo e conseguinte obtenção de crescimento sustentado.

Desse modo, vemos que a economia não pôde crescer acentuadamente porque o câmbio desestimulou as exportações e, não pode crescer mais rapidamente porque eliminou toda a poupança pública e tem dificuldades incitas representada pela expansão dramática das despesas públicas incluindo os juros. Assim, Netto (1998) defende que se tivermos sucesso na ampliação das exportações sem mexer no câmbio poderíamos voltar a crescer e isso seria algo inédito no mundo, porém o que se vê é que tal reversão rumo ao crescimento sustentado ainda não ocorreu.

\section{CONCLUSÕES}

Os anos 90 vão determinar um ponto de inflexão na trajetória da história econômica do Brasil, a partir da ruptura com o elevado padrão de proteção da economia nacional, característico do modelo de desenvolvimento até então implementado.

A estabilização macroeconômica, pré-requisito para a abertura comercial, que ressaltou a fragilidade competitiva da indústria nacional, ocorre do ponto de vista monetário, a partir da implementação da experiência de estabilização do Plano Real. Porém, os fundamentos do programa, baseados na valorização cambial e na elevação da taxa de juros, não permitem o esperado equilíbrio entre as variáveis macroeconômicas, sendo responsável por parte dos pontos de estrangulamento apresentados pela economia na década de 90 .

Revista de Estudos Sociais | Ano 2017, N. 39, V. 20, Pag. 162 
Desta forma, a motivação em realizar este trabalho foi mostrar o quanto o Plano Real foi relevante em termos de estabilização inflacionária ao mesmo tempo em que apresentou fragilidades pela incapacidade de assegurar o crescimento sustentável da economia brasileira. Tal fato, trouxe consequências econômicas e sociais.

Ainda que seja consenso na literatura econômica que o Plano Real foi bastante positivo para o país à medida que resgatou o poder de compra dos trabalhadores quando conseguiu controlar a inflação e elevou a produtividade das indústrias ao remeter a elas a responsabilidade pelos avanços no setor, este mesmo plano econômico não foi eficaz em estimular e/ou suscitar investimentos em expansão e desenvolvimento do parque industrial.

\section{REFERÊNCIAS BIBLIOGRÁFICAS}

ARIDA, P. e LARA RESENDE, A. Inflação Inercial e reforma monetária. ARIDA, P. (org.) Inflação zero - Brasil, Argentina e Israel. Rio de Janeiro: Paz e Terra, $3^{\text {a }}$ Ed., pp.9-35, 1986.

BACHA, E. L. O Plano Real: uma avaliação. MERCADANTE, A. (org.) O Brasil pósReal. Campinas: Instituto de Economia, UNICAMP, 1997.

BATISTA JR.; P. N. O Plano Real à luz da experiência mexicana e argentina. Estudos Avançados, n.10 (28), p. 129-197, 1996.

BOGDANSKI, J.; TOMBINI, A.; WERLANG, S. R. C. Implementing inflation targeting in Brazil. Working Paper Series. Brasília: Banco Central do Brasil, n.10, jul. 2000.

BRESSER PEREIRA, L. C. A economia e a política do Plano Real. Revista de Economia Política, v. 14, n. 4 (56), out/dez-1994.

CARNEIRO, R. Desenvolvimento em crise: a economia brasileira no último quarto do século XX. São Paulo: Editora UNESP, IE-Unicamp, 423 páginas, 2002.

CARVAlHO, C. E. As origens e a gênese do Plano Collor. Nova Economia, Belo Horizonte, v.16, n.1, jan/abr - 2006.

CASTRO, A. B. O Plano Real e o reposicionamento das empresas. In: VELLOSO, R. (Org.) Brasil: desafios de um país em transformação. 1997.

COUTINHO, L. O Desempenho da indústria sob o Real. In: MERCADANTE, A. (org.) O Brasil Pós- Real: a política econômica em debate. Campinas: UNICAMP I. E., 1998.

FARIA, L. A. E. Aquém da estagnação: 10 anos do Plano Real. Indicadores Econômicos; FEE, Porto Alegre, v. 32, n. 2, p. 175-196, 2004.

Revista de Estudos Sociais | Ano 2017, N. 39, V. 20, Pag. 163 
FILGUEIRAS, L. História do Plano Real: fundamentos, impactos e contradições. São Paulo: Boitempo, $3^{\mathrm{a}}$ ed., 2006.

FRANCO, G. Plano Real em perspectiva de médio prazo. In: VELLOSO, J. P. R. (Org.) O Brasil e o Mundo no limiar do novo século. Rio de Janeiro: José Olympio, p. 57-80, 1998.

FURTADO, C. Criatividade e dependência na civilização industrial. São Paulo: Editora Paz e Terra, 1978.

IBGE. Instituto Brasileiro de Geografia e Estatística. Inflação - IPCA - (\% a.a.) - 1980 a 2016. Sistema Nacional de Índices de Preços ao Consumidor. 2016.

LACERDA, A. C. de. O impacto da globalização na economia brasileira. São Paulo: Editora Contexto, 1998.

LARA, J. E.; CARVALHO MESQUITA, J. M. Estrutura de Capital e Rentabilidade: análise do desempenho de empresas brasileiras no período pós Plano Real. Contabilidade Vista \& Revista, UFMG; v. 19, n. 2, p. 15-33, 2008.

LOPES, H. C.; CONCEIÇÃO, O. A. C. A inflação e os Planos Cruzado e Real:uma interpretação institucionalista. Economia e Sociedade, Campinas, v. 25, n. 1 (56), p. 147 $172,2016$.

MOURA, B. O.; MARINHO, P. L. A influência de fatores macroeconômicos na internacionalização produtiva das empresas brasileiras no período 1995 a 2010. Anais do XII Congresso Brasileiro de História Econômica, Niterói RJ, ago-2017.

NETTO, A. D. O Plano Real e a armadilha do crescimento econômico. In: MERCADANTE, A (org.) O Brasil Pós-Real: a política econômica em debate. Campinas: UNICAMP IE, 1998.

OLIVEIRA, F. A. Recessão e inflação: o (des) ajuste neoliberal. São Paulo: Editora Hucitec; Campinas: Fundação Economia de Campinas, 1992.

PINHEIRO, A., GIAMBIAGI, F. e GOSTKORZEWICZ, J. O Desempenho Macroeconômico do Brasil nos anos 90. A Economia Brasileira nos anos 90. BNDES, Rio de Janeiro $1^{\text {a }}$ edição, 1999. 